\title{
Relationships between flavour and microbiological profiles in Serra da Estrela cheese throughout ripening
}

\author{
Stefan Dahl, Freni K. Tavaria, F. Xavier Malcata* \\ Escola Superior de Biotecnologia, Universidade Católica Portuguesa, Rua Dr. António Bernardino de Almeida, P-4200-072 Porto, Portugal
}

\begin{abstract}
Cheeses manufactured in certified dairies in the Portuguese region of Serra da Estrela, using refrigerated and non-refrigerated raw sheep milk, were quantitatively evaluated in terms of indigenous microflora and volatile compounds during a ripening period of up to 6 mo. Viable counts were obtained for lactococci, lactobacilli, leuconostoc, enterococci, yeasts, Enterobacteriaceae and staphylococci; analyses of volatiles were performed by chromatography after solid-phase micro-extraction. Treatment of all analytical data produced by principal component analysis revealed correlations between the major microbial groups present in cheese and patterns of volatiles generated. End products resulting from the degradation of sugars, free amino acids and glycerides constituted the predominant volatiles of Serra da Estrela cheeses. Among volatile, short-chain carboxylic acids detected were acetic, propionic, iso-butyric and iso-valeric acids; these compounds are known to be breakdown products of Gly, Ala and Ser, of Thr, of Val, and of Ile, respectively, following oxidative deamination. Semi-volatile fatty acids and their corresponding ethyl esters appeared in the cheese, probably as a result of the activity of lipases produced by yeasts and Enterobacteriaceae. These ethyl esters, which are responsible for fruity flavours, were especially pronounced in cheeses manufactured from refrigerated milk. (C) 2000 Elsevier Science Ltd. All rights reserved.
\end{abstract}

Keywords: Volatiles; Microorganisms; Dairy products

\section{Introduction}

Serra da Estrela cheese, probably the most famous among all Portuguese traditional cheeses, is manufactured at the farm level only from raw ewe's milk. The cheese is manufactured by following artisanal protocols which encompass coagulation with aqueous infusions of flowers of wild thistle (Cynara cardunculus), without the deliberate addition of any starter or non-starter cultures. Great variability is usually encountered between distinct dairies, and even within the same manufacturing batch. This variability obviously occurs owing to the lack of constancy of the microbiological, biochemical and physico-chemical characteristics of the cheese milk and the protocols of manufacture.

The flavour profile of a given food product is generally the most important criterion for consumers' preference. Development of unique aromas in cheeses is the result of

* Corresponding author. Tel.: +351-22-5580-004; fax: +351-225090-351. a complex set of interdependent reactions. Flavour studies describing a number of methods to extract odour fractions from Cheddar cheese date back to the mid1960s (Liebich, Douglas, Bayer \& Zlatkis, 1970) when extraction was carried out by steam distillation. From these efforts, the pattern of volatiles was correlated with the degree of cheese maturation (Banks, Brechany, Christie, Hunter \& Muir, 1992). Among short-chain free fatty acids that play a role in aroma, propionic, butyric, isobutyric and iso-valeric acids are usually noted; they are typically generated by oxidative deamination of free amino acids. Such medium-chain free fatty acids as hexanoic, octanoic and decanoic acids apparently originate from the lipolytic breakdown of milkfat (Urbach, 1995). On the other hand, ethanol, 2-alkanones, aldehydes and ethyl esters of butyric and hexanoic acids already occur in fresh milk, so they should not be exclusively implicated with microbial action during ripening (Urbach, 1995). After performing in vitro organic synthetic reactions between free amino acids and acetaldehyde, dihydroxiacetone and glutaraldehyde, Griffith and Hammond (1989) found that the free amino acids with the greatest 
potential to serve as flavour precursors were Val, Leu, Ile, Met, Cys, Phe, Pro and Lys. In fact, Strecker aldehydes, alcohols (following hydrogenation) and heterocyclic compounds (e.g. furanones and pyrazines) originate chemically therefrom; however, the same chemical mechanisms may not prevail in actual cheese systems.

The influence of pasteurization and fat composition of milk on the flavour characteristics of semi-hard cheeses was studied recently by Buchin et al. (1998). In their study, pasteurization reduced dramatically the viable numbers of all groups of indigenous microorganisms (as expected), particularly coliforms, lactobacilli and enterococci; this fact affected the extent and nature of the volatiles formed throughout ripening. Milky- and butter-like flavours were attributed to high concentrations of 2,3-butanedione (or diacetyl) and 2,3-pentanedione, which were detected in cheese manufactured from pasteurized milk. However, cheese milk pasteurization was not found to affect the extent of proteolysis, an observation that contrasts with data of Grappin and Beuvier (1997).

Bosset and Gauch (1993) compared the flavour patterns of six different European Appéllation d'Origine Controllée (AOC) cheeses. These investigators reported that virtually all the cheeses analysed contained qualitatively the same constituents, but at distinctly different concentrations. Their major conclusion was that the typical flavour associated with each specific cheese does not depend on plain existence of the so called "key compounds', but rather on their relative concentrations (Engels, 1997).

The major objective of this study was to correlate microbiological and volatile compound patterns found in Serra da Estrela cheese via use of multivariate analysis, and to eventually confirm the linking of certain groups of microorganisms with specific flavour compounds. Previous work in this area encompassing traditional Portuguese cheeses was extremely scarce, and in all cases unable to back up statistically significant conclusions.

\section{Materials and methods}

\subsection{Cheese manufacture and sampling}

Five batches of Serra da Estrela cheese were simultaneously manufactured according to traditional procedures (Macedo, Malcata \& Oliveira, 1993) in each of the four selected certified dairies of the AOC region. Each batch of milk in each dairy produced a total of 10 independent cheeses, each one weighing ca. $1 \mathrm{~kg}$. Sampling consisted of choosing two cheeses at random (which were thus considered as true replicates) for each one of five ripening times $(60,90,120,150$ and $180 \mathrm{~d}$; sampling between 0 and $60 \mathrm{~d}$ was not done because previous experience had indicated that the amounts of volatile fla- vour compounds were virtually negligible within this period). Representative samples from each cheese were obtained, after the rind had been removed, by cutting a thin slice through the innermost, the intermediate and the outermost layers of the cheese and combining all three of them to produce a single 10-g cheese aliquot; this aliquot was aseptically handled and homogenized for 2 min using 2\% (w/v) aqueous sodium citrate (Merck, Darmstadt, Germany) as extraction buffer in a Stomacher Lab-Blender 400 (Seward Medical, London, UK). After sampling for microbiological analyses, cheeses were stored as 50 -g portions at $-30^{\circ} \mathrm{C}$ until chemical analyses were carried out.

\subsection{Microbiological analyses}

Aliquots of $1 \mathrm{~mL}$ were taken from fresh cheese samples (after the due ripening period), decimally diluted in sterile $0.1 \%(\mathrm{w} / \mathrm{v})$ aqueous peptone (Sigma Chemical, St. Louis MO, USA), and then plated in duplicate on several selective (or elective, when otherwise not available) media: Violet Red Bile Glucose agar (VRBGA, Merck, Germany) for Enterobacteriaceae; Rogosa agar (RA, Merck), acidified with acetic acid to $\mathrm{pH}$ 5.4, for lactobacilli; M17 agar (M17, Merck) for lactococci; Mayeux, Sandine and Elliker agar (MSE, Merck) for leuconostoc; KF-Streptococcus agar (KF, Merck), with $10 \mathrm{~mL} \mathrm{~L}^{-1}$ of $1 \%(\mathrm{w} / \mathrm{v})$ aqueous 2,3,5-triphenyltetrazolium chloride for enterococci; Baird-Parker agar (BPA, Lab M, Ref. 85, Amersham, UK) with $50 \mathrm{~mL} \mathrm{~L}^{-1}$ of sterile egg-yolk tellurite (Lab M, Ref. X085), for staphylococci; and Potato Dextrose agar (PDA, Lab M, Ref. 98), acidified with $10 \mathrm{~mL} \mathrm{~L}^{-1}$ of $10 \%(\mathrm{v} / \mathrm{v})$ sterile lactic acid, for yeasts. The spread plate technique was used for all media except VRBGA; for this, the pour plate technique was used instead. VRBGA, KF and BPA plates were incubated aerobically at $37^{\circ} \mathrm{C}$ for $1-2 \mathrm{~d}$; PDA plates were incubated aerobically at $30^{\circ} \mathrm{C}$ for $3-5 \mathrm{~d}$; plates containing the other media were incubated anaerobically at $30^{\circ} \mathrm{C}$ using anaerobiosis-producing catalysts (BBL Gas Pak Plus ${ }^{\mathrm{TM}}$, Cockeysville MD, USA).

\subsection{Chemical analyses}

Volatiles released from the thawed cheese samples after frozen storage (for no longer than $30 \mathrm{~d}$ at $-30^{\circ} \mathrm{C}$ ) were assessed using solid-phase micro-extraction (SPME) of the headspace atmosphere, following the method described by Chin, Bernhard and Rosenberg (1996) with minor modifications to more effectively fit our needs. Aliquots of the cheese samples described before, weighing $20 \pm 0.2 \mathrm{~g}$, were taken and placed in a $500 \mathrm{~mL}$, three-necked round bottom flask. After having closed the flask with the SPME-injection adapter containing a preconditioned SPME fiber, $\mathrm{N}_{2}$ was continuously flushed through the other inlet port and the entire 
assembly was kept in a thermostatically controlled water bath $\left(60^{\circ} \mathrm{C}\right)$. Once the adsorption process was over, the fiber was removed and the accumulated volatiles were thermally desorbed at $220^{\circ} \mathrm{C}$.

The fiber used was a polyacrylate fiber (thickness of $85 \mu \mathrm{m}$ ), which was able to quantitatively adsorb most components of interest. The volatile components adsorbed from the SPME fiber were analysed using a Perkin-Elmer gas chromatograph (AutoSystem XL, Norwalk CT, USA) with a DB-Wax column (30 $\mathrm{m} \times$ $0.32 \mathrm{~mm} \times 0.25 \mu \mathrm{m}$ ) from $\mathrm{J} \& \mathrm{~W}$ Scientific (Folsom CA, USA). Data aquisition and analysis was accomplished by using the Turbochrome ${ }^{\mathrm{TM}}$ software from Perkin-Elmer. Peak identification was achieved by comparing retention times with those of pure standards.

\subsection{Statistical analyses}

The experimental data pertaining to viable numbers within each microbial group were subjected to a logarithmic transformation in order to stabilize variance and normalize the distribution of residuals. Analysis of variance (ANOVA) (on the assumption of a completely ran- domized design), was conducted for the viable numbers of the different microbial groups, to verify the significance of the effects of the dairy farm and the time of ripening. Multivariate analysis (via Principal Component Analysis) was applied to all data (i.e. transformed microbiological data and chemical data) using the Statistica Software package (StatSoft, 1993).

\section{Results and discussion}

\subsection{Microbiological analyses}

The average counts (and corresponding standard deviations) of viable lactobacilli, lactococci, leuconostoc, enterococci, yeasts, Enterobacteriaceae and staphylococci found in cheeses produced from non-refrigerated milk in the four independent dairies are plotted in Fig. 1. ANOVA indicated that both the dairy farm and the time of ripening were significant $(p<0.05)$ for all microbial groups, except ripening time with respect to enterococci. The average values (and corresponding standard deviations) of viable counts of those microbial groups
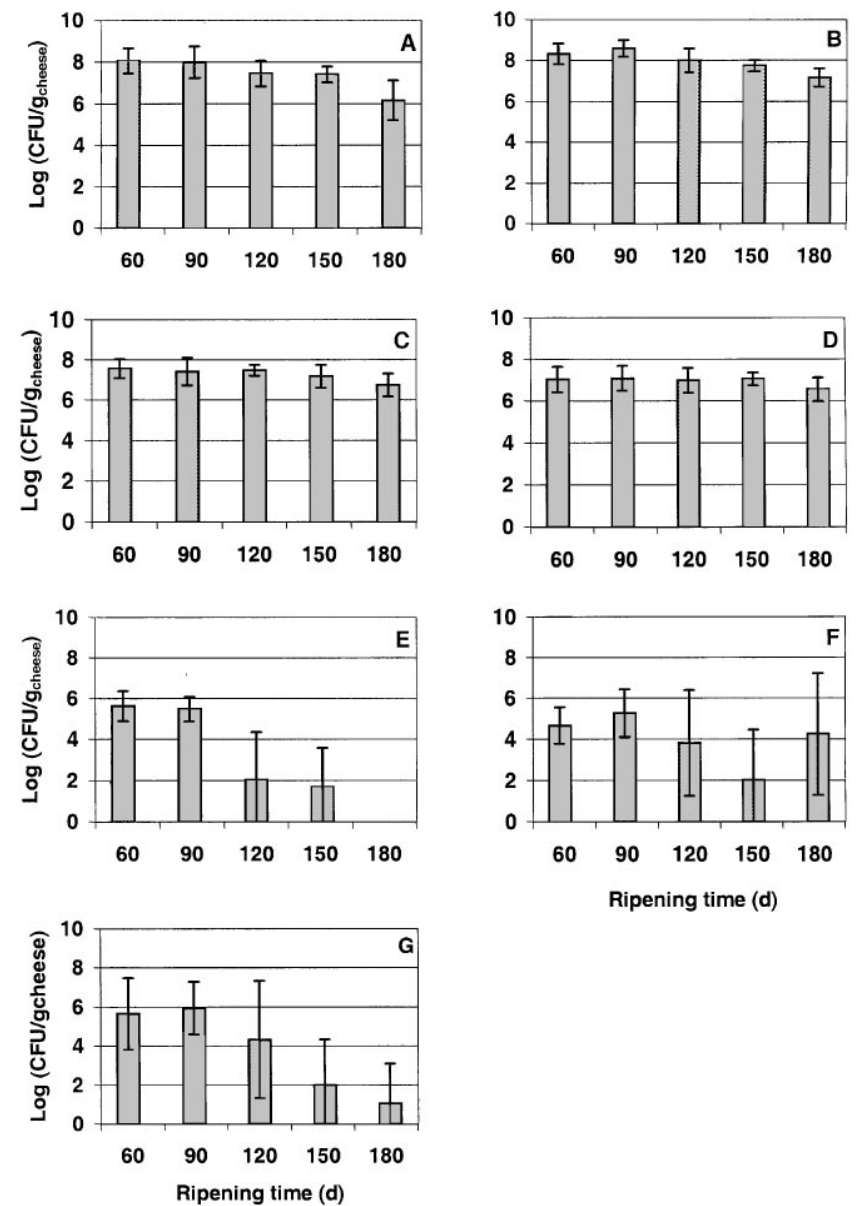

Fig. 1. Mean values (from the four dairies) and corresponding standard deviations (I) of viable counts of lactobacilli (A), lactococci (B), leuconostoc (C), enterococci (D), Enterobacteriaceae (E), staphylococci $(\mathrm{F})$ and yeasts $(\mathrm{G})$ in cheeses produced from non-refrigerated milk and ripened up to $180 \mathrm{~d}$. 
Table 1

Mean values and corresponding standard deviations of viable counts in cheeses produced from non-refrigerated and refrigerated milk in dairy A

\begin{tabular}{|c|c|c|c|c|c|c|c|}
\hline Ripening time & Lactococci & Lactobacilli & Enterococci & Leuconostoc & Enterobacteriaceae & Staphylococci & Yeasts \\
\hline \multicolumn{8}{|c|}{ Cheeses manufactured from non-refrigerated milk } \\
\hline 60 & $8.68 \pm 0.09$ & $8.46 \pm 0.05$ & $7.31 \pm 0.01$ & $8.24 \pm 0.20$ & $5.70 \pm 0.24$ & $5.70 \pm 0.45$ & $7.33 \pm 0.22$ \\
\hline 120 & $8.77 \pm 1.77$ & $7.77 \pm 0.63$ & $6.67 \pm 0.16$ & $7.83 \pm 0.02$ & $4.19 \pm 0.54$ & $5.57 \pm 0.51$ & $5.79 \pm 0.36$ \\
\hline 150 & $8.05 \pm 0.14$ & $7.54 \pm 0.43$ & $7.34 \pm 0.94$ & $7.95 \pm 0.19$ & $3.02 \pm 0.00$ & $5.00 \pm 1.51$ & $1.20 \pm 0.00$ \\
\hline 180 & $7.62 \pm 0.17$ & $6.21 \pm 0.09$ & $7.37 \pm 0.30$ & $7.59 \pm 0.10$ & $0.00 \pm 0.00$ & $6.86 \pm 0.02$ & $0.00 \pm 0.00$ \\
\hline 60 & $8.36 \pm 0.09$ & $8.18 \pm 0.10$ & $7.03 \pm 0.04$ & $8.00 \pm 0.11$ & $4.14 \pm 1.12$ & $3.91 \pm 0.80$ & $4.91 \pm 0.09$ \\
\hline 90 & $8.28 \pm 0.02$ & $8.38 \pm 0.05$ & $7.15 \pm 0.01$ & $7.93 \pm 0.40$ & $3.58 \pm 0.99$ & $6.69 \pm 0.73$ & $4.34 \pm 0.17$ \\
\hline 120 & $8.13 \pm 0.25$ & $8.12 \pm 0.14$ & $7.10 \pm 0.04$ & $8.08 \pm 0.29$ & $0.00 \pm 0.00$ & $6.50 \pm 0.71$ & $7.23 \pm 0.14$ \\
\hline 150 & $8.32 \pm 0.23$ & $8.29 \pm 0.06$ & $6.92 \pm 0.64$ & $8.18 \pm 0.20$ & $0.00 \pm 0.00$ & $5.53 \pm 0.66$ & $6.53 \pm 0.57$ \\
\hline 180 & $7.94 \pm 0.05$ & $8.02 \pm 0.16$ & $7.14 \pm 0.41$ & $7.95 \pm 0.03$ & $0.00 \pm 0.00$ & $6.84 \pm 0.83$ & $1.20 \pm 0.00$ \\
\hline
\end{tabular}

found in cheeses manufactured with refrigerated and non-refrigerated milk in one selected dairy are compared in Table 1. The ANOVA revealed that refrigeration vs. non-refrigeration was significant for Enterobacteriaceae and lactobacilli viable numbers, and that the ripening time was significant $(p<0.05)$ for Enterobacteriaceae, lactobacilli, staphylococci and yeasts viable numbers.

Lactic acid bacteria (i.e. lactobacilli, lactococci, leuconostoc and enterococci) were quantitatively the dominant groups for all ripening times and for all dairies, with viable numbers ranging from $10^{7}$ to $10^{9} \mathrm{CFU} \mathrm{g}$ cheese . These results, which are typical of semi-hard cheeses, are comparable to those reported for other artisanal cheeses originated in Portugal (Macedo, Freitas, Tavaria \& Malcata, 1997; Tavaria \& Malcata, 1998), Spain (Fontecha et al., 1990; Fernandez del Pozo, Gaya, Medina, Rodriguez-Marin \& Nuñez, 1988; González de Llano, Ramos, Rodriguez, Montilla \& Juárez, 1992) and Greece (Tzanetakis, Litopoulou-Tzanetaki \& Manolkidis, 1987).

There was a sharp decrease in the numbers of Enterobacteriaceae and yeasts ( $82 \%$ ) between 60 and $180 \mathrm{~d}$ of ripening, with most of the microbial death occuring after $120 \mathrm{~d}$ of maturation. After $120 \mathrm{~d}$, there was only an $18 \%$ further decrease in the viable numbers of staphylococci, which is not surprising because these microorganisms are known to be able to survive under adverse environmental conditions (Nuñez, Medina \& Gaya, 1989).

\subsection{Analysis of volatile compounds}

Table 2 shows the main volatile compounds found in cheeses manufactured from non-refrigerated and refrigerated ewe's milk, and relative odour thresholds (owing to the complexity of the method employed and the number of fibers required, analytical replicates were not obtained). As happened with the microbiological assays, a great variability in chemical composition was observed between samples obtained from different dairies, probably owing to the non-standardized process of manufac- ture. In general, these cheeses were characterized by high amounts of alcohols and short-chain acids, rather than ketones as found by Buchin et al. (1998) for raw milk cheeses when compared with pasteurized milk cheeses; this observation was likely due to the specific indigenous microflora. Appearance of higher levels of 2,3-butanediol in cheeses (Engels, 1997), when produced from nonrefrigerated milk (Table 2), confirms a high activity of spoilage bacteria in Serra da Estrela cheese. In addition, high concentrations of ethyl-octanoate and -decanoate reveal yeast activity resulting from lipolysis rather than amino acid decay. All cheeses exhibited a notable buildup of volatile short-chain fatty acids throughout the ripening period; however, there was an apparent decrease in caprylic and capric acids in the 180-d samples, with maxima already attained by $150 \mathrm{~d}$. The presence of 1 octanol and 2-nonanone, which is a result of the metabolism by lactic acid bacteria (Law \& Sharpe, 1973), was observed after $150 \mathrm{~d}$, the period during which these strains were dominant.

The pattern of volatiles was qualitatively richer in the cheeses made from refrigerated milk (Table 2). These cheeses showed higher concentration in ethyl esters of almost all fatty acids, which contribute fruity notes to flavour. This observation is usually ascribed to lipolytic activity brought about by psychrotrophic bacteria and yeasts (Molimard \& Spinnler, 1996).

Studies (Fernández-García, 1996) encompassing aroma development of Afuega'l Pitu cheese followed an experimental design similar to the one followed in our work. This particular acid-coagulated cheese is a homemade variety produced in Asturias from bovine raw milk. Ethanol, diacetyl, acetoin, Strecker alcohols and acetic acid were found to predominate in the first 2 weeks of ripening, while fatty acid ethyl esters, acetaldehyde and sulfur compounds increased their concentration during the following 2 weeks. In artisanal Gamonedo blue cheese (González de Llano et al., 1990), the volatile fraction of ripened cheeses was very rich in FFA, methyl 
Table 2

Comparison of the volatile components present in Serra da Estrela cheese throughout maturation (in ppm)

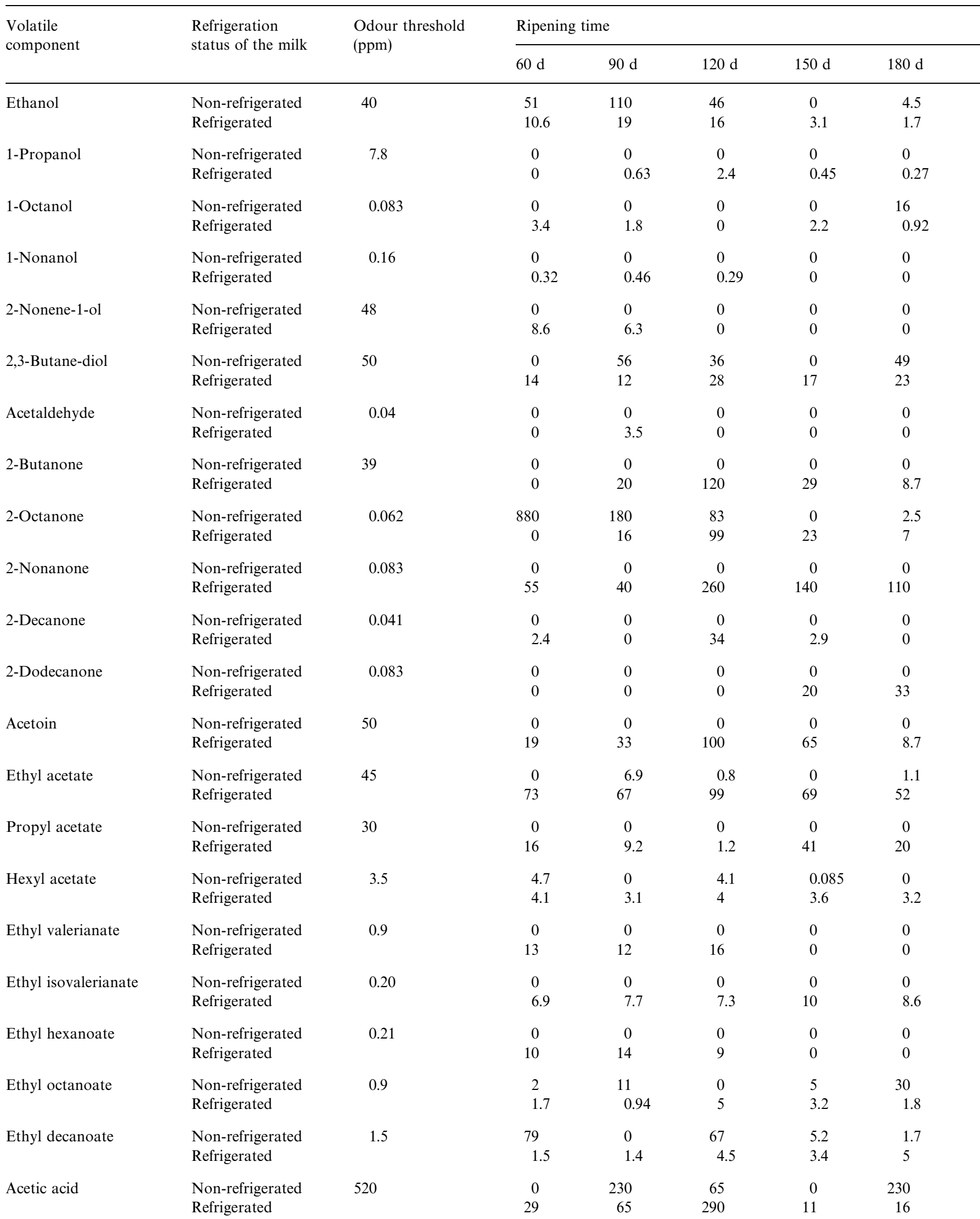


Table 2 (continued)

\begin{tabular}{|c|c|c|c|c|c|c|c|}
\hline \multirow{2}{*}{$\begin{array}{l}\text { Volatile } \\
\text { component }\end{array}$} & \multirow{2}{*}{$\begin{array}{l}\text { Refrigeration } \\
\text { status of the milk }\end{array}$} & \multirow{2}{*}{$\begin{array}{l}\text { Odour threshold } \\
\text { (ppm) }\end{array}$} & \multicolumn{5}{|c|}{ Ripening time } \\
\hline & & & $60 \mathrm{~d}$ & $90 \mathrm{~d}$ & $120 \mathrm{~d}$ & $150 \mathrm{~d}$ & $180 \mathrm{~d}$ \\
\hline Propionic acid & Refrigerated & 5.0 & 16 & 19 & 23 & 24 & 31 \\
\hline Iso-butyric acid & Non-refrigerated & 9.5 & 0 & 140 & 220 & 0 & 0 \\
\hline Butyric acid & Refrigerated & 4.8 & 110 & 500 & 600 & 520 & 390 \\
\hline \multirow[t]{2}{*}{ Iso-valeric acid } & Non-refrigerated & \multirow[t]{2}{*}{2.7} & 640 & 710 & 880 & 340 & 230 \\
\hline & Refrigerated & & 380 & 370 & 290 & 410 & 710 \\
\hline Valeric acid & Non-refrigerated & 4.6 & 0 & 130 & 55 & 25 & 46 \\
\hline \multirow[t]{2}{*}{ Caproic acid } & Non-refrigerated & \multirow[t]{2}{*}{0.9} & 530 & 920 & 570 & 270 & 210 \\
\hline & Refrigerated & & 500 & 470 & 800 & 500 & 510 \\
\hline \multirow[t]{2}{*}{ Caprylic acid } & Non-refrigerated & \multirow[t]{2}{*}{1.9} & 160 & 120 & 160 & 230 & 100 \\
\hline & Refrigerated & & 170 & 120 & 310 & 160 & 120 \\
\hline \multirow[t]{2}{*}{ Capric acid } & Non-refrigerated & \multirow[t]{2}{*}{5.0} & 53 & 56 & 51 & 120 & 45 \\
\hline & Refrigerated & & 58 & 32 & 120 & 53 & 26 \\
\hline
\end{tabular}

ketones and 2-alkanols. Manchego cheese, a Spanish cheese manufactured from raw ewes' milk, using a plantderived milk coagulant similar to that used to produce Serra da Estrela cheese, is probably the best example of another cheese for comparative purposes. In Manchego cheese the microflora is similar, and is dominated by Lactococcus lactis, whereas enterococci, leuconostocs, streptococci, micrococci and yeasts are present at lower levels (Martínez-Castro, Sanz, Amigo, Ramos \& Martin-Alvarez, 1991). Volatiles, like in Serra da Estrela cheese, included free fatty acids, 2-alkanones and ethyl esters of fatty acids with an even number of carbon atoms. In a soft, raw goat's milk cheese (Sablé, Letellier $\&$ Cottenceau, 1997), the heptan-2-one, nonan-2-one, their corresponding secondary alcohols, some esters and sulfur compounds were associated with the manufacturing process, which in turn influenced microbial activity. Like in Domiati cheese (Collin, Osman, Delcambre, El-Zayat \& Dufour, 1993), ester production may be attributable to the parallel increase of the short- and medium-chain fatty acid concentration that results from the hydrolysis of fat by enterococci and lactobacilli, which are quite abundant in the Serra da Estrela cheeses under investigation.

\subsection{Statistical analyses}

Principal component analysis was conducted so as to search for correlations between 35 variables measured, including microbiological viable counts and volatile compound concentrations. Factor analysis resulted in the first two eigenvalues being able to explain ca. $85 \%$ of the variability of the dataset for cheeses manufactured from non-refrigerated milk, and ca. $79 \%$ for those produced from refrigerated milk. Better correlations between concentrations of volatiles and viable numbers of microorganisms were found for cheeses produced from refrigerated milk than from non-refrigerated milk (Table 3).

In terms of significant correlations $(p<0.05)$, it became apparent that lactococci numbers were correlated with valeric acid and 2,3-butanediol concentrations; lactobacilli with acetaldehyde; leuconostoc with ethyl acetate and nonanol; staphylococci with isobutyric and butyric acids; Enterobacteriaceae with $n$-propanol, acetoin, acetic acid, 2-nonanone, $n$-nonanol, ethyl octanoate and ethyl decanoate; and yeasts with $n$-propanol, 2-butanone, acetic acid, 2,3-butanediol, caproic acid, capric acid, caprylic acid, 2-nonanone, $n$-nonanol, ethyl octanoate and ethyl decanoate. These correlations indicate that the latter compounds are probably secondary metabolites of the former microbial groups.

Cheeses from dairy B were unique with respect to the presence of volatile degradation products originating from spoilage microflora (mostly yeasts), i.e. diacetyl, acetoin, 2,3-butanediol and 2-butanone. In cheeses from this dairy, the number of yeasts remained high (ca. $10^{5} \mathrm{~g}_{\text {cheese }}^{-1}$ ) up to $180 \mathrm{~d}$ of ripening, whereas in products 
Table 3

Significant correlation coefficients $(p<0.05)$ between volatile components and microorganisms found in cheeses produced from non-refrigerated and refrigerated milk

\begin{tabular}{|c|c|c|}
\hline $\begin{array}{l}\text { Volatile } \\
\text { component }\end{array}$ & $\begin{array}{l}\text { Refrigeration } \\
\text { status of milk }\end{array}$ & $\begin{array}{l}\text { Microorganism } \\
\text { (Correlation coefficient) }\end{array}$ \\
\hline Ethanol & Non-refrigerated & $\begin{array}{l}\text { Leuconostoc }(0.52) \\
\text { Yeasts }(0.57)\end{array}$ \\
\hline Acetic acid & Non-refrigerated & Staphylococci $(0.55)$ \\
\hline Butyric acid & $\begin{array}{l}\text { Non-refrigerated; } \\
\text { Refrigerated }\end{array}$ & $\begin{array}{l}\text { Enterococci }(0.53) \\
\text { Staphylococci }(0.64) \\
\text { Enterobacteriaceae }(-0.53)\end{array}$ \\
\hline Iso-valeric acid & Non-refrigerated & $\begin{array}{l}\text { Enterobacteriaceae }(0.55), \\
\text { Yeasts }(0.59)\end{array}$ \\
\hline Caproic acid & Non-refrigerated & $\begin{array}{l}\text { Enterobacteriaceae }(0.51), \\
\text { Yeasts }(0.53)\end{array}$ \\
\hline Hexyl-acetate & Non-refrigerated & $\begin{array}{l}\text { Enterococci }(-0.51) \text {, } \\
\text { Yeasts }(0.50)\end{array}$ \\
\hline Acetaldehyde & Refrigerated & Lactobacilli (0.62) \\
\hline$n$-Propanol & Refrigerated & Yeasts $(0.57)$ \\
\hline 2-Butanone & Refrigerated & Yeasts $(0.55)$ \\
\hline Ethyl acetate & Refrigerated & Leuconostoc $(0.64)$ \\
\hline Acetoin & Refrigerated & Yeasts $(0.81)$ \\
\hline Acetic acid & Refrigerated & Yeasts $(0.56)$ \\
\hline 2,3-Butanediol & Refrigerated & $\begin{array}{l}\text { Enterobacteriaceae }(-0.51) \text {, } \\
\text { Lactococci }(-0.79)\end{array}$ \\
\hline iso-Butyric acid & Refrigerated & Staphylococci $(-0.81)$ \\
\hline Valeric acid & Refrigerated & $\begin{array}{l}\text { Lactococci }(-0.87) \\
\text { Lactobacilli }(-0.54)\end{array}$ \\
\hline 2-Nonanone & Refrigerated & $\begin{array}{l}\text { Enterobacteriaceae }(-0.79) \text {, } \\
\text { Yeasts }(0.55)\end{array}$ \\
\hline Nonanol & Refrigerated & Enterobacteriaceae (0.99) \\
\hline Caprylic acid & Refrigerated & Yeasts $(0.59)$ \\
\hline Ethyl-octanoate & Refrigerated & $\begin{array}{l}\text { Enterobacteriaceae }(-0.54) \text {, } \\
\text { Yeasts }(0.61)\end{array}$ \\
\hline Capric acid & Refrigerated & Yeasts $(0.66)$ \\
\hline Ethyl-decanoate & Refrigerated & $\begin{array}{l}\text { Enterobacteriaceae }(-0.73) \text {, } \\
\text { Enterococci }(-0.55)\end{array}$ \\
\hline
\end{tabular}

from the other three dairies they decreased to negligible viable numbers already by $120 \mathrm{~d}$ of ripening.

As seen above, by $90 \mathrm{~d}$ of ripening cheeses produced from refrigerated milk possessed higher numbers of viable yeasts than cheeses produced from non-refrigerated milk, a fact which may reflect a higher oxidative environment prevailing in the former, and thus preferential presence of more oxidized forms of acetoin derivatives, e.g. diacetyl or 2,3-butanediol.

Free amino acids often present in Serra da Estrela cheese in significant concentrations (Tavaria, unpub- lished data) were found to be leucine, valine, proline, phenylalanine and glycine. They are the chemical precursors (Fox \& Wallace, 1997) of isovaleric acid, isobutyric acid, 2-acetylpyrrolidone, phenylethanol and acetaldehyde, respectively, all of which play important roles in flavour. Of these volatiles, isobutyric and isovaleric acids and acetaldehyde were especially pronounced in cheeses made from refrigerated milk. According to Barbieri et al. (1994), acetaldehyde, ethanol, diacetyl and acetoin are associated with activity of lactic acid bacteria, with valine and leucine playing the role of anabolites in synthesis of aroma precursors. In our samples, cheeses from refrigerated milk exhibited higher numbers of lactic acid bacteria and lower numbers of Enterobacteriaceae, which may appear as a competitive advantage.

In cheeses produced from non-refrigerated milk, the most relevant correlations found in the PCA (Table 3) were between: Enterobacteriaceae and yeasts with isovaleric acid; enterococci and staphylococci with butyric acid; and yeasts and leuconostoc with ethanol. In cheeses manufactured from refrigerated milk (Table 3), the most relevant correlations were between: Enterobacteriaceae and 2-nonanol; lactococci and valeric acid; staphylococci and iso-butyric acid; and yeasts and acetoin.

\section{Conclusions}

The diversity found in artisanal cheeses, in terms of microbiological and chemical profiles, was confirmed in this work. Lactic acid bacteria belonging to the Lactobacillus, Lactococcus and Enterococcus genera constituted the dominant microflora throughout the entire ripening period. The numbers of yeasts and Enterobacteriaceae decreased significantly after $120 \mathrm{~d}$ of ripening, hence suggesting that most volatiles formed after this time could be accounted for by the activity of lactic acid bacteria. Numbers of Enterobacteriaceae, yeasts and staphylococci declined sharply, to almost negligible levels, thus suggesting that spontaneous microbial interactions will eventually drive this dynamic food system into a microbiologically safer product after 4 months of ripening. At this age, the non-starter lactic acid bacteria that prevail in Serra da Estrela cheese likely control proliferation of certain undesirable bacteria.

In cheeses manufactured from refrigerated milk, the numbers of Enterobacteriaceae, enterococci and yeasts were significantly lower than those encountered in cheeses produced from non-refrigerated milk; therefore, it is suggested that this processing practice may prevent extensive growth of unwanted microorganisms.

Volatiles originating from the degradation products of sugars (mainly lactose), free amino acids (especially valine and leucine) and lipids (free fatty acids) were found. Semi-volatile fatty acids and their corresponding ethyl 
esters were probably produced by lipases released from yeasts and Enterobacteriaceae.

\section{Acknowledgements}

Financial support for authors Dahl and Tavaria were provided by a Post-Doctoral (PBD-11838/97) and Ph.D. fellowships (BD-9572/96), respectively, issued by the Foundation for Science and Technology (FCT) within program PRAXIS XXI, Portugal. Partial financial support for this project was obtained from project grants Control, acceleration and diversification of cheese flavour formed by enzymatic conversion of amino acids (FAIR-CT 97-3173, EU), IMPACTO-Investigação dirigida ao Melhoramento do Processo de produção do queijo serrA por integração de abordagens Científicas e TecnOlógicas (PRAXIS XXI, Portugal) and PROTOLACTIS-PROdução, por Tecnologias Optimizadas, de LACticínios TradicionaIS (PAMAF, Portugal). The authors are grateful to the members of the technological board of ANCOSE (the Portuguese Association of Breeders of Serra da Estrela Sheep) for cheese manufacture according to the required specifications, transport of experimental ripened cheeses to our premises and topical discussions.

\section{References}

Banks, J. M., Brechany, E. Y., Christie, W. W., Hunter, E. A., \& Muir, D. D. (1992). Volatile components in steam-distillates of Cheddar cheese as indicator indices of cheese maturity, flavour and odour. Food Research International, 25, 365-373.

Barbieri, G., Bolzoni, L., Careri, M., Mangia, A., Parolari, G., Spagnoli, S., \& Virgili, R. (1994). Study of the volatile fraction of Parmesan cheese. Journal of Agricultural and Food Chemistry, 42, 1170-1176.

Bosset, J. O., \& Gauch, R. (1993). Comparison of the volatile flavour compounds of six European 'AOC' cheeses by using a new dynamic headspace GC-MS method. International Dairy Journal, 3, 359-377.

Buchin, S., Delague, V., Duboz, G., Berdague, J. L., Beuvier, E., Pochet, S., \& Grappin, R., (1998). Influence of pasteurization and fat composition of milk on the volatile compounds and flavor characteristics of a semi-hard cheese. Journal of Dairy Science, 81, 3097-3108.

Chin, H. W., Bernhard, R. A., \& Rosenberg, M. (1996). Solid phase microextraction for cheese volatile compound analysis. Journal of Food Science, 61, 1118-1121.

Collin, S., Osman, M., Delcambre, S., El-Zayat, A., \& Dufour, J.-P. (1993). Investigation of volatile flavor compounds in fresh and ripened Domiati cheeses. Journal of Agricultural and Food Chemistry, 41, 1659-1663.

Engels, W. (1997). Volatile and non-volatile compounds in ripened cheese: their formation and their contribution to flavour. Ph.D. dissertation, University of Agriculture, Wageningen, The Netherlands.
Fernandez del Pozo, B., Gaya, P., Medina, M., Rodriguez-Marin, A., \& Nuñez, M. (1988). Changes in the microflora of La Serena ewe's milk cheese during ripening. Journal of Dairy Research, 55, 449-455.

Fernández-García, E. (1996). Use of headspace sampling in the quantitative analysis of artisanal Spanish cheese aroma. Journal of Agricultural and Food Chemistry, 44, 1833-1839.

Fontecha, J., Pelaez, C., Juárez, M., Requena, M. T., Gómez, C., \& Ramos, M. (1990). Biochemical and microbiological characteristics of artisanal hard goat's cheese. Journal of Dairy Science, 73, 1150-1157.

Fox, P. F., \& Wallace, J. M. (1997). Formation of flavour compounds in cheese. Advances in Applied Microbiology, 45, 17-85.

González de Llano, D., Ramos, M., Rodriguez, A., Montilla, A., \& Juárez, M. (1992). Microbiological and physicochemical characteristics of Gamonedo blue cheese during ripening. International Dairy Journal, 2, 121-135.

Grappin, R., \& Beuvier, E. (1997). Possible implications of milk pasteurization on the manufacture and sensory quality of ripened cheese: a review. International Dairy Journal, 7, 751-761.

Griffith, R., \& Hammond, E. G. (1989). Generation of Swiss cheese flavor components by reaction of amino acids with carbonyl components. Journal of Dairy Science, 72, 604-613.

Law, B.A., \& Sharpe, M.E. (1973). Lactic acid bacteria and flavour in cheese. In: Lactic acid bacteria in beverages and food. Proceedings of a symposium held at Long Ashton Research Station, University of Bristol (pp. 233-243).

Liebich, H. M., Douglas, D. R., Bayer, E., \& Zlatkis, A. (1970). The volatile flavor components of Cheddar cheese. Journal of Chromatographic Science, 8, 355-359.

Macedo, A., Freitas, A. C., Tavaria, F. K., \& Malcata, F. X. (1997). Portuguese traditional cheeses: native microbiota. In: Microflora (Mastering the influence of microorganisms on the final properties of raw milk cheeses) (pp. 55-63). Editrice Tecnograf, Reggio nell'Emilia, Italy.

Macedo, A. C., Malcata, F. X., \& Oliveira, J. C. (1993). Review on the technology, microbiology, and chemistry of Serra cheese. Journal of Dairy Science, 76, 1725-1739.

Martínez-Castro, I., Sanz, J., Amigo, L., Ramos, M., \& Martín-Alvarez, P. (1991). Volatile compounds of Manchego cheese. Journal of Dairy Research, 58, 239-246.

Molimard, P., \& Spinnler, H. E. (1996). Review: compounds involved in the flavour of surface mold-ripened cheeses: origins and properties. Journal of Dairy Science, 79, 169-184.

Nuñez, M., Medina, M., \& Gaya, P. (1989). Ewe's milk cheese: technology, microbiology and chemistry. Journal of Dairy Research, 56, 303-321.

Sablé, S., Letellier, F., \& Cottenceau, G. (1997). An analysis of the volatile flavour compounds in a soft raw goat milk cheese. Biotechnology Letters, 19, 143-145.

StatSoft (1993). Statistica for Windows, v. 4.5.

Tavaria, F. K., \& Malcata, F. X. (1998). On the microbiology of Serra da Estrela cheese: geographical and chronological considerations. Food Microbiology, in press.

Tzanetakis, N., Litopoulou-Tzanetaki, E., \& Manolkidis, K. (1987). Microbiology of Kopanisti, a traditional Greek cheese. Food Microbiology, 4, 251-256.

Urbach, G. (1995). Contribution of lactic acid bacteria to flavour compound formation in dairy products. International Dairy Journal, 5, 877-903. 